Trivent Publishing

(C) The Authors, 2016

Available online at http://trivent-publishing.eu/

Series: Philosophy, Communication, Media Sciences

Volume: Communication Today: An Overview from Online Journalism to Applied Philosophy

\title{
Using Modern Methods to Solve Geometry Problems
}

\author{
Lupu Costică
}

\begin{abstract}
"Vasile Alecsandri" University of Bacău, România, Faculty of Science, Mathematics-Informatics and Science of Education Departament 157 Mărăşeşti Street, Bacău, 600115, România, costica_lupu @ub.ro
\end{abstract}

\begin{abstract}
The tests and studies of this research demonstrated the effectiveness of teaching with the use of computers in solving problems and fostering knowledge of Geometry, the development of active thinking and training of skills, as well as abilities in representing Geometric figures in plan.

The experimental lot is consists of 112 students of seventh grade students from the "Octavian Voicu" Middle School of Bacău (Romania). We used the formative type of the pedagogical experiment in order to verify the impact of using active-participative methods and modern techniques for teaching-learning-evaluating elements of Geometry relating to the points in plan.
\end{abstract}

\section{Keywords:}

Experimental research; computing technology; geometric representations; remarkable points.

This is an Open Access article distributed in accordance with the Creative Commons Attribution Non Commercial (CC-BYNC-ND 4.0) license, which permits others to copy or share the article, provided original work is properly cited and that this is not done for commercial purposes. Users may not remix, transform, or build upon the material and may not distribute the modified material (http://creativecommons.org/licenses/by-nc/4.0/)

DOI: 10.22618/TP.PCMS.20164.349013 


\section{Introduction}

Computing technology is used in education in order to increase the efficiency of education in educational environments. Computer technology promotes learning by creating an attractive and effective learning environment. ${ }^{1}$

There are many types of educational software that can be found on the market to do exercises, calculations, simulations, programming, database development and other applications. The greatest advantage of computers is that they can operate more sophisticated and complex software.

All these developments led students at the Faculty of Mathematics, "Vasile Alecsandri" University of Bacău, to new approaches in designing the activity in Geometry lessons, with many effects on strengthening knowledge of Geometry in a way which actively develops the students' abilities to represent geometric figures and space. ${ }^{2}$

Comparing the results of the initial test and the final qualifier is found insufficient decrease from $7 \%$ to $0 \%$ and a growth percentage of good and very good ratings from $71 \%$ to $96 \%$. From histogram with initial and final test results are observed how very well the 21 qualifiers, $37 \%$, are obtained 30 qualifiers very well, $52 \%$.

The results obtained by the pupils confirm the hypothesis of our work. Thus, we found that the use of modern means in the teaching-learning-evaluation of knowledge during Geometry lessons contributes to enhancing learning, rendering it efficient, stimulating the pupils' intellectual and creative potential, obtaining performances according to age and individual particularities.

Richard E.M. ${ }^{3}$ states that the influx existing information technology and computer classrooms in recent years they put teachers and students to use computers in instructing her children and investigate using learning mathematics Matlab and GeoGebra in the construction of geometric figures. I choose for illustration a few applications remarkable.

Lupu C. ${ }^{4}$ highlights the contribution of new technologies in learning mathematics through online libraries and Internet sources may become relevant once students have successfully covered an eLearning program so that mathematical knowledge can be strengthened, implemented and evaluated.

\section{Paper theoretical foundation. Remarkable applications}

Bayer O., Lazebnik F.D., Smeltzer L. ${ }^{5}$ shows a variety of methods to solve problems in Euclidean geometry and Grigorieva E. ${ }^{6}$ presents methods and solutions for various problems of planar geometry.

\section{A. Nagel's point}

If $A^{\prime}, B^{\prime}$ and $C^{\prime}$ are contact points of the circles in the sides of the triangle $A B C\left(A^{\prime} \in(B C), B^{\prime} \in\right.$ (AC), $\left.C^{\prime} \in(A B)\right)$ the sides $A A^{\prime}, B B^{\prime}$ and $C C^{\prime}$ are concurrent, in a point named, Nagel's point. (Fig.1.) Demonstration.

\footnotetext{
${ }^{1}$ C. Keitel-Kreidt and K. Ruthven, Learning from Computers: Mathematics Education and Technology (Springer Science \& Business Media, 2012), 75.

${ }^{2}$ C. Lupu, "Methods of Demonstrating the Collinearity of Points in Space," in Procedia - Social and Behavioral Sciences 180 (London: Elsevier, 2015), 847-853.

${ }^{3}$ E.M. Richard, Teaching and Learning Computer Programming: Multiple Research Perspectives (London: Routledge 2013), 112.

${ }^{4}$ C. Lupu, "The Contribution of the New Technologies to Learning Mathematics," in Procedia-Social and Behavioral Sciences 128 (London: Elsevier, 2014), 240-245.
} 


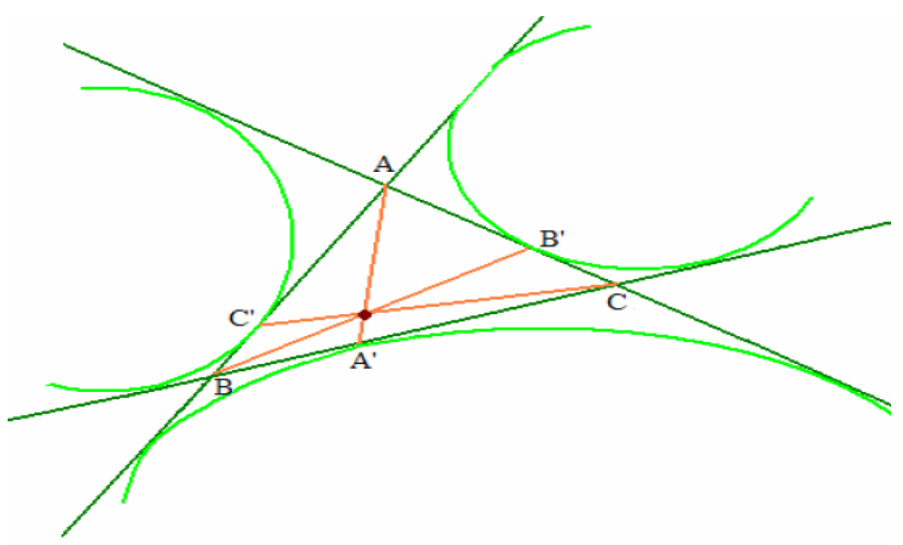

Fig.1. The sides $A A^{\prime}, B B^{\prime}$ and $C C^{\prime}$ are concurrent

If $a, b, c$ the length of the triangle's sides $(B C=a, A C=b, A B=c)$ and $p$ the semiperimetre of the triangle. We write $x=B A^{\prime}, y=A^{\prime} C$ and we have: $x+y=a$ and $x+c=y+b$ where $2 x+c=a+b$, and $x=p-c$ and $y=p-b$. We get: $\frac{A^{\prime} B}{A^{\prime} C}=\frac{p-b}{p-c}$. Analogically we have: $\frac{B^{\prime} C}{B^{\prime} A}=\frac{p-c}{p-a}$ and $\frac{C^{\prime} A}{C^{\prime} B}=\frac{p-a}{p-b}$. Multiplying the three relations we have $\frac{A^{\prime} B}{A^{\prime} C} \cdot \frac{B^{\prime} C}{B^{\prime} A} \cdot \frac{C^{\prime} A}{C^{\prime} B}=1$, and according to the reciproqual of the theorem of Ceva the sides $A A^{\prime}, B B^{\prime}$ and $C C^{\prime}$ are concurrent. ${ }^{5}$

\section{B. Gergone's point}

In a triangle $\mathrm{ABC}$ the sides which unite the vertexes of the triangle with the contact points of the inside circle with the opposed sides are concurrent in a point (named Gergonne's point) (Fig.2). Demonstration.

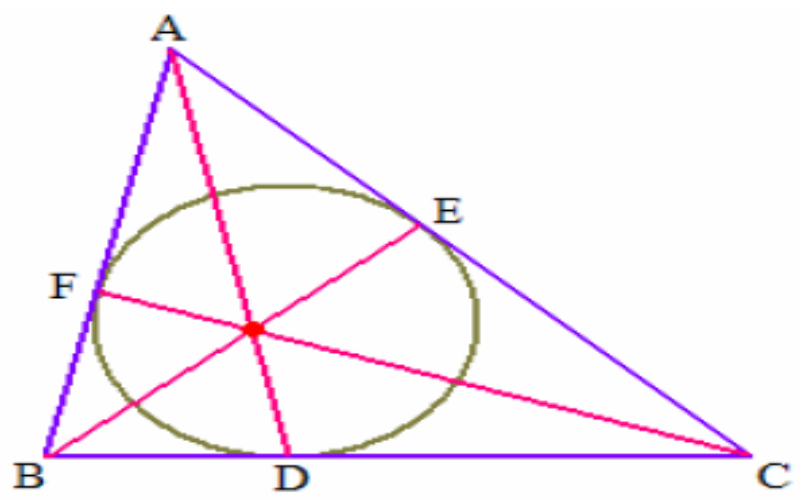

Fig.2. The sides $A D, B E$ and $C F$ are concurrent

We write the contact points with $D, E$ and $F$, where $\mathrm{D} \in B C, E \in A C$ and $F \in A B$. We use the reciproqual of the theoreme of Ceva to show the relation: $\frac{D B}{D C} \cdot \frac{E C}{E A} \cdot \frac{F A}{F B}=1\left(^{*}\right)$. But $B D \equiv B F, C E \equiv C D$ and $A E \equiv A F$ (tangents in an exterior point in a circle are congruents). The relation (*) is evident, meaning that $A D, B E$ and $C F$ are concurrent in a point.

${ }^{5}$ O. Byer, F. Lazebnik, D. L. Smeltzer, Methods for Euclidian Geometry (Mathematical Association of America. Classroom Resource Materials, MAA textbooks, 2010), 32. 


\section{Newton's point}

$A B C D$ a quadrangle, $A^{\prime}, B^{\prime}, C^{\prime}$ and $D^{\prime}$ the tangent points of the circle with the sides of the quadrangle. The sides $A C, B D, A^{\prime} C^{\prime}$ and $B^{\prime} D^{\prime}$ cross the same point $N$, named Newton's point. ${ }^{6}$ (Fig.3). Demonstration.

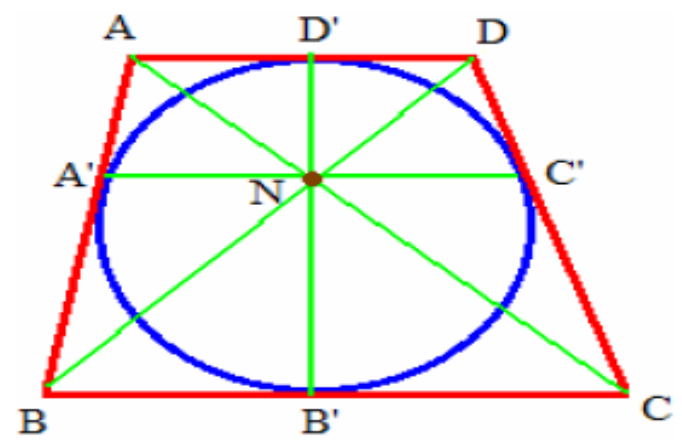

Fig.3.The sides $A C, B D, A^{\prime} C^{\prime}$ and $B^{\prime} D^{\prime}$ are concurrent

We write with $\{N\}=A C \cap B^{\prime} D^{\prime}, a=m\left(\Varangle A D^{\prime} N\right)$ and $b=m\left(\Varangle A N D^{\prime}\right)$. We observe that $\mathrm{m}\left(\measuredangle \mathrm{ND}^{\prime} \mathrm{A}\right)+\mathrm{m}\left(\measuredangle \mathrm{NB}^{\prime} \mathrm{C}\right)=180^{\circ}$. Applying the theoreme of the sinuses in the triangles $\mathrm{NAD}^{\prime}$ and NB'C we get: $\frac{A D^{\prime}}{\sin b}=\frac{A N}{\sin a} ; \frac{B^{\prime} C}{\sin b}=\frac{C N}{\sin a}$. From these two equalities we have: $\frac{A N}{C N}=\frac{A D^{\prime}}{C B^{\prime}}(1),\left\{N^{\prime}\right\}=A C$ $\cap A^{\prime} C^{\prime}$. Applying the same method we get: $\frac{A N^{\prime}}{N^{\prime} C}=\frac{A A^{\prime}}{C C^{\prime}}$ (2). As $A A^{\prime}=A D^{\prime}, C C^{\prime}=C B^{\prime}$, from (1) and (2) we have $N=N^{\prime}$, so $A C$ crosses the meeting of the sides $A^{\prime} C^{\prime}$ and $B^{\prime} D^{\prime}$. Analogically we demonstrate that $N \in B D$.

\section{Miquel's point}

$\mathrm{ABCD}$ a convex quadrangle and $\{\mathrm{E}\}=\mathrm{AB} \cap \mathrm{CD},\{\mathrm{F}\}=\mathrm{BC} \cap \mathrm{AD}$. The circles circumscribed the triangles $\mathrm{ABF}, \mathrm{ADE}, \mathrm{CFD}$ and $\mathrm{ECB}$ cross the same point M, Miquel's point. (Fig.4).

Demonstration.

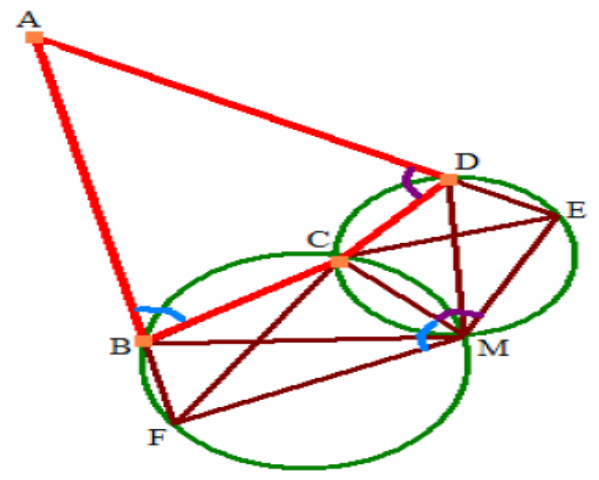

Fig.4. The point $M$ belongs to the circumscribed circles of the triangles $A B F, A D E, C B E$ and $C D F$

Being $M$ a second meeting point of the circumscribed triangles $B C E$ and $D C F$. As $\measuredangle C M E \equiv \measuredangle C B A$ and $\measuredangle C M F \equiv \measuredangle C D A$ results that $m(\measuredangle B A F)+m(\measuredangle B M F)=m(\measuredangle B A F)+m(\measuredangle B M C)+m(\measuredangle C M F)$

\footnotetext{
${ }^{6}$ E. Grigorieva, Methods for solving complex geometry problems (Boston: Birkhauser, 2013), 137.
} 
$=m(\measuredangle E A D)+m(\measuredangle A E D)+m(\measuredangle A D E)=180^{\circ}$. The quadrangle $A D M E$ is in scriptable. So, the point $M$ belongs to the circumscribed circles of the triangles $A B F, A D E, C B E$ and $C D F$.

\section{Research Methodology}

The purpose of this research has been to verify the followings:

- the efficiency of applying modern means to Mathematics for Geometry, in executing plane figures and geometrical solids by using programs for graphic and geometrical drawing;

- improving the teaching of Mathematics by means of the new technologies provided by the laboratories equipped with computers connected to an internal network and with the interactive whiteboard;

- the integration into the teaching and evaluation process of the new technologies and of the computer, within the curriculum;

- enhancing the students' interest in studying, by means of using the computer, highly loved by the students;

- creating new educational software, lessons and tests, using the computer;

- attracting students towards studying, by using modern methods, involving the use of the new technologies and the computer.

\section{A. Research objectives}

Our research was based on the following fundamental objective: modern means support knowledge acquisition and improve the level of Mathematical knowledge, build the competence to demonstrate and solve problems of Geometry, eventually accomplishing the goals of intellectual education.

The research objectives were related to:

1. Increasing the efficiency of the teaching-learning-evaluation activities for Geometry.

2. Building skills in executing plane figures and plane and space geometrical shapes.

3. Diversifying the students' learning experiences by accessing new learning strategies and methods.

4. Building the students' skills in using modern means during lessons of Mathematics, through active participation, creativity stimulation.

\section{B. The research hypothesis}

If we use active-participative methods, modern means and techniques for teaching-learning-evaluating elements of Geometry, students will build skills in using modern means in solving problems with a geometrical content, amplifying the retention of contents and school progress.

\section{Research methods}

In our research, we have used the following methods: observation; conversation; analysis of activity products.

\footnotetext{
7 V. Popa, Carte pentru tinerii profesori de matematică [Book for young teachers of mathematics], (Bacau: Publishing Egal, 2004), 27.
} 
We have used the formative type of pedagogical experiment in order to verify the impact of using active-participative methods and modern means and techniques for teaching-learning-evaluating elements of Geometry related competition straight lines the remarkable points in plan. (Table 1.).

The following stages have been covered:

- initial testing of the experimental and control group, with a view to evaluating Mathematical knowledge, at the start of the 2014-2015 school year - through a predictive test;

- introducing the progress factor, respectively solving problems, using the active-participative methods and modern teaching-learning-evaluation means and techniques in solving problems of concurrence the geometric lines of points in plan.

- the final testing of the experimental and control group, to highlight the impact of the progress factor upon the acquisition of contents and school progress.

The experiment has provided quantitative and qualitative data, with a high degree of precision (Table 2.); the data have been conclusive, processed and interpreted with the help of statisticalmathematical methods and techniques.

In ordering and grouping the data, we have resorted to the following statistical techniques:

- summary tables of results - analytical (recording the individual results of the investigated subjects) and synthetic (grouping the measured data) (Table 3.);

- forms of graphical representation: the histogram, the frequency polygon and the round diagram (Figure 5).

The statistical method was used to process, analyse, systematize and interpret the data obtained following the measurements. The data from the synthetic tables were graphically represented through: histograms, frequency polygons and round diagrams.

Data processing consisted in ordering, systematizing and correlating empirical data with the purpose of substantiating a decision regarding the statistical significations of these data in relation to the hypothesis.

Once grouped, the first data have been centralized in certain analytical and synthetic tables. After each testing, we have drawn a centralizing table, in which the rows display the number of items and the columns the number of students. The measuring tool was the percentage report and the measuring unit was the students' mark. After centralizing the data, we have drawn the histogram, round diagram and frequency polygon, in order to show the progress achieved from the initial to the summative test.

Table 1. Performance Descriptors

\begin{tabular}{|c|c|c|c|}
\hline \multirow[t]{2}{*}{ Items } & \multicolumn{3}{|c|}{ Qualifying } \\
\hline & Sufficient & Good & Very good \\
\hline $\mathrm{I}_{1}$ & $\begin{array}{l}\text { Drawing plan figure obtained } \\
\text { by computer several errors }\end{array}$ & $\begin{array}{l}\text { Drawing plan figure obtained by } \\
\text { computer some errors }\end{array}$ & $\begin{array}{l}\text { Drawing plan figure obtained } \\
\text { by computer without errors }\end{array}$ \\
\hline $\mathrm{I}_{2}$ & $\begin{array}{lll}\text { Identify correctly all } 3 \\
\text { competing geometric lines. }\end{array}$ & $\begin{array}{l}\text { Identify correctly all } 6 \text { competing } \\
\text { geometric lines. }\end{array}$ & $\begin{array}{lcc}\text { Identify correctly all } & 9 \\
\text { competing geometric lines. } & \\
\end{array}$ \\
\hline $\mathrm{I}_{3}$ & Solve problems with support. & $\begin{array}{l}\text { Identifies the operation that } \\
\text { solves problems, but with } \\
\text { computational errors. }\end{array}$ & $\begin{array}{l}\text { Solve and demonstrate } \\
\text { problems correctly. }\end{array}$ \\
\hline $\mathrm{I}_{3}$ & $\begin{array}{l}\text { Correctly solve a problem } 1 \\
\text { using the reciproqual of the } \\
\text { theoreme of Ceva }\end{array}$ & $\begin{array}{l}\text { Correctly solve two problem } 1 \\
\text { using the reciproqual of the } \\
\text { theoreme of Ceva }\end{array}$ & $\begin{array}{l}\text { Correctly solve all three } \\
\text { problem } 1 \text { using the reciproqual } \\
\text { of the theoreme of Ceva }\end{array}$ \\
\hline $\mathrm{I}_{4}$ & $\begin{array}{l}\text { Correctly solve a problem } 2 \\
\text { using theoreme of the sinuses }\end{array}$ & $\begin{array}{l}\text { Correctly solve two problem } 2 \\
\text { using theoreme of the sinuses }\end{array}$ & $\begin{array}{ll}\text { Correctly } & \text { solve all three } \\
\text { problem } 2 & \text { using theoreme of } \\
\text { the sinuses } & \end{array}$ \\
\hline $\mathrm{I}_{5}$ & $\begin{array}{l}\text { Correctly solve a problem } 3 \\
\text { using circumscribed circles of } \\
\text { the triangles }\end{array}$ & $\begin{array}{l}\text { Correctly solve two problem } 3 \\
\text { using circumscribed circles of the } \\
\text { triangles }\end{array}$ & $\begin{array}{l}\text { Correctly solve all three } \\
\text { problem } 3 \text { using circumscribed } \\
\text { circles of the triangles }\end{array}$ \\
\hline $\mathrm{I}_{6}$ & Solve problems with support. & $\begin{array}{l}\text { Identifies the operation that } \\
\text { solves problems, but with } \\
\text { computational errors. }\end{array}$ & $\begin{array}{l}\text { Solve and demonstrate } \\
\text { problems correctly. }\end{array}$ \\
\hline
\end{tabular}


Table 2. Scoring set for each item

\begin{tabular}{|l|l|l|l|}
\hline Items & Points & Items & Points \\
\hline $\mathrm{I}_{1}$ & 15 points & $\mathrm{I}_{5}$ & 15 points \\
\hline $\mathrm{I}_{2}$ & 12 points & $\mathrm{I}_{6}$ & 21 points \\
\hline $\mathrm{I}_{3}$ & 12 points & Ex officio & 10 points \\
\hline $\mathrm{I}_{4}$ & 15 points & & \\
\hline
\end{tabular}

Transformation of scores into marks: $\mathrm{I}=$ below 50 points; $\mathrm{S}=50-69$ points; $\mathrm{B}=70-89$ points; $\mathrm{FB}=90-100$ points.

\section{Research results}

Table 3. Results -experimental and control sample

\begin{tabular}{|l|l|l|l|l|}
\hline Qualifying & Insufficient & Sufficient & Good & Very good \\
\hline Experimental sample & 0 & 2 & 24 & 30 \\
\hline Control sample & 4 & 6 & 20 & 26 \\
\hline
\end{tabular}

Based on the table, there were generated:

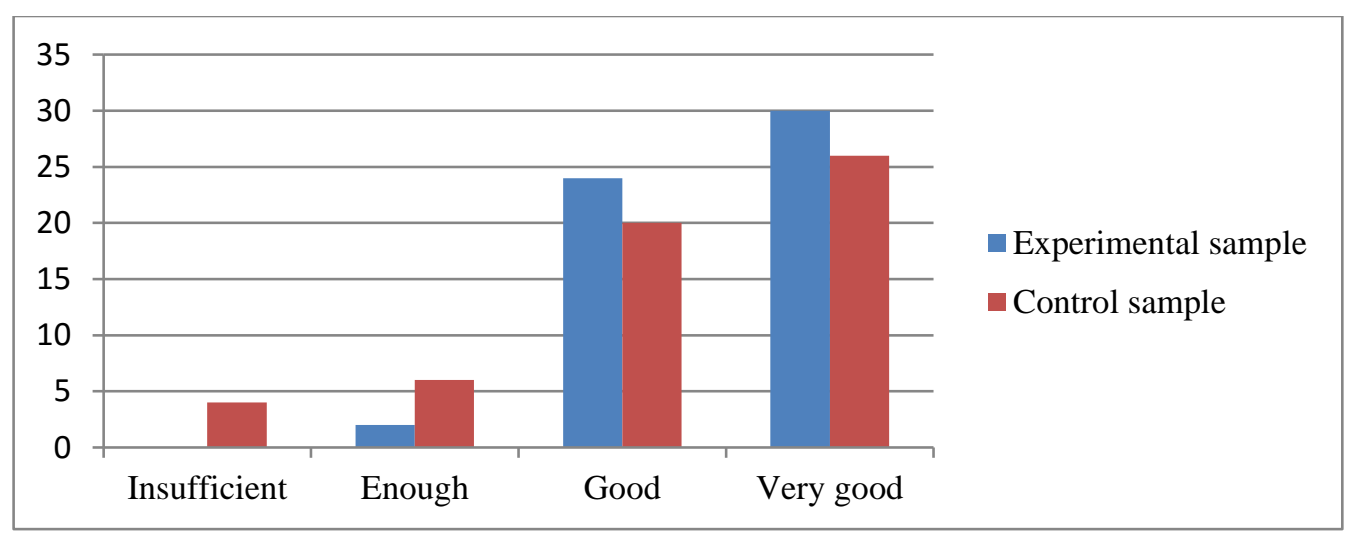

Fig.5. The comparative histogram between the experimental and control sample

Comparing the results of the two samples, we may find that those of the experimental group are better. The students have achieved progress percentage increases to $82 \%$ in the control to $96 \%$ in the experimental group. This fact shows that the motivation of students for learning has grown, as well as their level of knowledge.

Table 4. Comparative table with experimental sample results from the three tests

\begin{tabular}{|l|l|l|l|l|}
\hline Mark & Insufficient & Enough & Good & Very good \\
\hline Initial test & 4 & 12 & 19 & 21 \\
\hline Formative test & 2 & 11 & 19 & 24 \\
\hline Summative test & 0 & 2 & 24 & 30 \\
\hline
\end{tabular}

Comparing the results of the initial test and the final qualifier is found insufficient decrease from $7 \%$ to $0 \%$ and a growth percentage of good and very good ratings from $71 \%$ to $96 \%$. From histogram with 
initial and final test results are observed how very well the 21 qualifiers, $37 \%$, are obtained 30 qualifiers very well, $52 \%$. The recorded results have confirmed of the research, highlighting the fact that the students' school progress may be significantly influenced by the use of active methods and modern means in solving problems of concurrence the geometric lines of points in plan.

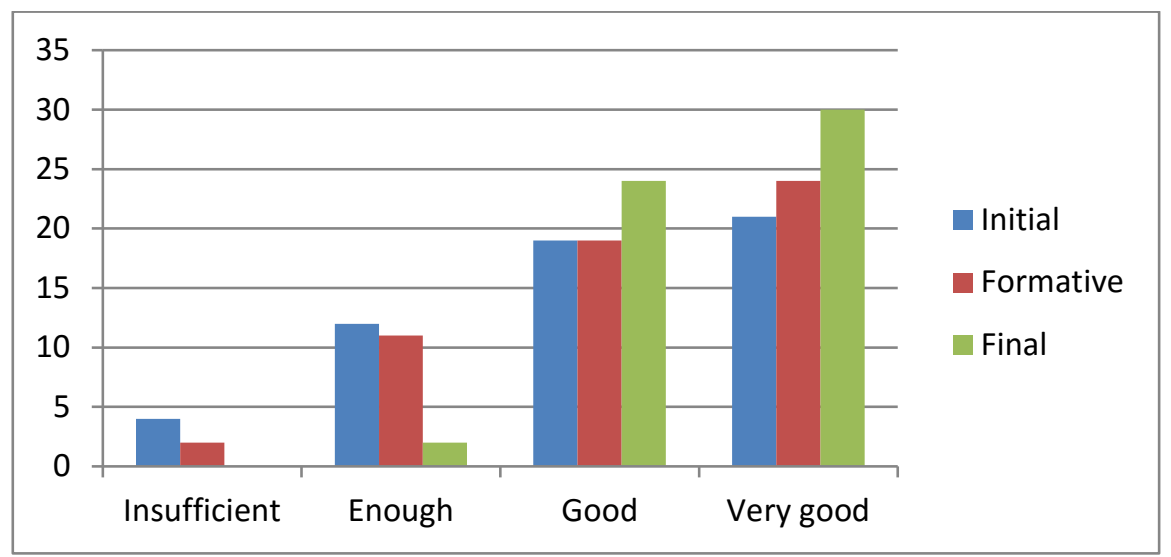

Fig. 6. The Histogram with the results to the initial and final tests

\section{Discussions}

The blue columns indicate the results obtained by the students in the initial test and the green columns represent the results for the final test. It is obvious that the students have made progress, particularly as a consequence of the active methods used in building skills and knowledge at students from primary education.

At the moment, universities have turned into a relevant factor in the initial and professional training of an individual. Through the departments of teacher pedagogical and professional training, universities have gained the freedom to make their own decisions regarding the way in which the graduates of these institutions are trained professionally, and this autonomy of the institution accompanies the evolution of the job market and the demands existing in this sector.

Assuming the role of trainer, the educational institution should find a way to adapt to these exigencies, so that it may offer its direct and main beneficiaries, students, the needed skills and ability to use them (both during their studies and after graduation). In other words, the aim is to broaden the range of skills acquired by the students, through a qualitative education, based on the multitude of competences, rather than one centred on the quantity of the acquired material. Following this idea, the direct way towards achieving the intended aim is related to turning to advantage the benefits provided by cutting-edge technology.

By rendering the way in which the teaching material is presented efficient and ensuring a higher quality to the training process, the school will provide its students with the premises needed to develop their skills in the given time. Digital, multimedia libraries and externalized skills visibly change the perspective upon the educational practice. Introducing computers, interactive whiteboards and Internet connection in schools bring about changes in the educational sphere.

The new information and communication technologies - the computer and the interactive whiteboard - are suitable for numerous types of applications in training, to the direct or indirect benefit of the learners. Relative to the teaching-learning activities, all these tools fulfil one of the following roles: resources for classroom activities; support in the teaching activity; support in activating students. There are applications which address the learners directly, in order to help them acquire information or certain competences, by means of demonstrations, examples, illustrations, simulations. 


\section{Conclusions}

The students from the $3^{\text {rd }}$ year from the Faculty of Mathematics have made use of the new technologies in the teaching-learning-evaluation of the collinearity of three points in plan, through: - elaborating lesson plans, tests, calculus sheets, diplomas etc. - recording the students' progress and analysing the data by managing the data bases, the table calculus, the special programs for statistical analysis. preparing and delivering presentations which involved the use of graphic tools, programs of writing equations, presentation software (Power Point), video processing systems.

Students of four classes of seventh graders, two of them with 56 students in the experimental sample and two of 56 students from the control sample from "Octavian Voicu" Middle School of Bacău, participants in the formative-ameliorative experiment, have made use of these useful resources in the fast, easy and efficient accomplishment of individual work tasks, through: writing the essays from their portfolios on solving problems of concurrence the geometric lines of points in plan.

The pupils and students made use of text processors, equation editors and the DTP systems for these types of tasks; developing products and presentations using: Algebraic and Geometrical graphs, multimedia/ hypermedia authoring programs, presentation software, video processing software.

The pupils overcame barriers in solving concurrence problems by applying the five methods for demonstrating concurrence, have searched new solving ways through the trial-error approach. They have manifested proper behaviour in relation to their work-group peers, during the practical activities of solving problems.

Combining the forms of frontal, group and individual work has generated possibilities for multiple and diverse activations of pupils with a view to solving problems. The conscious effort made by each pupil in solving a problem has implied a great activation of the physical knowledge, volitional and motivational emotional processes: thought, memory, imagination, language, will, motivation and attention.

\section{References}

Byer, O. and F. Lazebnik, D.L. Smeltzer. Methods for Euclidian Geometry. Mathematical Association of America. Classroom Resource Materials. MAA texbooks, 2010.

Grigorieva E. Methods for solving complex geometry problems. Boston: Birkhauser, 2013.

Henk, J.M. Redefining Geometrical Exactness: Descartes' Transformation of the Early Modern Concept of Construction .New York: Springer Science \& Business Media, 2012.

Keitel-Kreidt, C. and K. Ruthven. Learning from Computers: Mathematics Education and Technology. New York: Springer Science \& Business Media, 2012.

Lupu, C. "The Contribution of the New Technologies to Learning Mathematics." In Procedia-Social and Behavioral Sciences 128. London: Elsevier, 2014: 240-245.

Lupu, C.. "Methods of Demonstrating the Collinearity of Points in Space." In Procedia - Social and Behavioral Sciences 180. London: Elsevier, 2015: p. 847-853.

Popa, V. Carte pentru tinerii profesori de matematică [Book for young teachers of mathematics]. Bacau: Publishing Egal, 2004.

Postolică V. and Lupu C. "Euclidean Geometry and Computers". In International Journal of Applied Science and Mathematics 2 (2015):1-5.

Richard E.M. Teaching and Learning Computer Programming: Multiple Research Perspectives. London: Routledge, 2013. 